\title{
Subsidies and Countervailing Duties with Firm Heterogeneity
}

\author{
Jota Ishikawa $^{\mathrm{a}^{*}}$ and Yoshimasa Komoriya ${ }^{\mathrm{a}}$
}

${ }^{a}$ Hitotsubashi University

\begin{abstract}
The WTO allows importing countries to impose countervailing duties (CVDs) when subsidies provided in exporting countries cause serious injuries. This paper examines the effects of CVDs as well as those of subsidies. Using an international oligopoly model, direct export subsidies and capital subsidies are explored in the presence of heterogeneity among recipients. All recipient firms gain from export subsidies, but this may not be the case for capital subsidies. The maximum CVD allowed under the WTO rules may be more than enough to offset the injury caused by a capital subsidy.
\end{abstract}

JEL Classification: F12, F21, F23

Keywords: subsidies, countervailing duties, heterogeneous firms

\section{Introduction}

In the seminal work of strategic trade policy, Brander and Spencer (1985) showed that export subsidies may raise domestic welfare by shifting rent from foreign firms to domestic firms. This welfare-enhancing effect is in contrast with the welfare-reducing effect in the traditional trade models under perfect competition. ${ }^{1}$ Since then, subsidies to oligopolistic industries have attracted considerable attention in the international trade literature.

${ }^{*}$ Corresponding author: Faculty of Economics, Hitotsubashi University, Kunitachi, Tokyo 186-8601, Japan. Fax: +81-42-580-8882. E-mail: jota@econ.hit-u.ac.jp. The authors are grateful to an anonymous referee and participants of the 2007 APJAE Symposium on Strategic Trade Theory and Economic Development for helpful comments and suggestions. All remaining errors are the authors' own responsibility. Financial support from the Ministry of Education, Culture, Sports, Science and Technology of Japan under the 21st Century Center of Excellence Project is acknowledged.

${ }^{1}$ Itoh and Kiyono (1987) show that export subsidies may enhance welfare in a Ricardian model with a continuum goods (i.e., a so-called Dornbush-Fischer-Samuelson model). 
Under the Agreement on Subsidies and Countervailing Measures of the Word Trade Organization (WTO), subsidies are not only grants but also other measures benefiting recipients. Examples include tax exemptions, loan guarantees and government procurement. The WTO prohibits export subsidies and subsidies contingent upon the use of domestic over imported goods. These prohibited subsidies are called "red-light" subsidies. Subsidies that are not prohibited per se but have specificity are called "yellowlight" subsidies. Importing countries may impose countervailing duties (CVDs) when serious injuries are caused by red-light and yellow-light subsidies. Under the WTO rules, however, the revenue of a CVD may not exceed the payment of the subsidy found to exist. ${ }^{2}$ In fact, Article 19.2 says "It is desirable ... that the duty should be less than the total amount of the subsidy if such lesser duty would be adequate to remove the injury to the domestic industry..."

Table 1

Number of CVD Investigations and Outstanding Countervailing Measures (1995-2006)

\begin{tabular}{|c|c|c|c|c|c|c|c|c|c|c|c|c|c|}
\hline \multicolumn{14}{|c|}{ Number of Investigations } \\
\hline & 95 & 96 & 97 & 98 & 99 & 00 & 01 & 02 & 03 & 04 & 05 & 06 & Total \\
\hline US & 3 & 1 & 6 & 12 & 11 & 7 & 18 & 4 & 5 & 3 & 2 & 0 & 72 \\
\hline Australia & 0 & 0 & 1 & 0 & 1 & 0 & 0 & 1 & 3 & 0 & 0 & 0 & 6 \\
\hline Canada & 3 & 0 & 0 & 0 & 3 & 4 & 1 & 0 & 1 & 4 & 1 & 1 & 18 \\
\hline $\mathrm{NZ}$ & 1 & 4 & 1 & 0 & 0 & 0 & 0 & 0 & 0 & 0 & 0 & 0 & 6 \\
\hline $\mathrm{EU}$ & 0 & 1 & 4 & 8 & 19 & 0 & 6 & 3 & 1 & 0 & 3 & 0 & 45 \\
\hline Japan & 0 & 0 & 0 & 0 & 0 & 0 & 0 & 0 & 0 & 1 & 0 & 0 & 1 \\
\hline \multicolumn{14}{|c|}{ Number of Outstanding Measures } \\
\hline & \multicolumn{2}{|c|}{ US } & \multicolumn{2}{|c|}{ Australia } & \multicolumn{2}{|c|}{ Canada } & \multicolumn{2}{|c|}{$\mathrm{NZ}$} & \multicolumn{2}{|c|}{$\mathrm{EU}$} & \multicolumn{2}{|c|}{ Japan } & \\
\hline & \multicolumn{2}{|c|}{45} & \multicolumn{2}{|c|}{1} & \multicolumn{2}{|c|}{10} & \multicolumn{2}{|c|}{4} & \multicolumn{2}{|c|}{23} & \multicolumn{2}{|c|}{1} & \\
\hline
\end{tabular}

Source: Industrial Structure, Council, METI, Japan (2007)

CVDs have been observed widely. In particular, the United States and the EU have frequently utilized CVDs (see Table 1). Recently, the United States has also made preliminary decisions to impose CVDs on glossy paper from Indonesia, South Korea and China. ${ }^{3}$ It should be mentioned that CVDs have often caused friction between importing and exporting countries. Typically, facing CVDs, exporting countries claim that they

\footnotetext{
${ }^{2}$ No countervailing duty shall be levied on any imported product in excess of the amount of the subsidy found to exist, calculated in terms of subsidization per unit of the subsidized and exported product (Article 19.4).

${ }^{3}$ The decision is notable, because the United States alters a 23-year-old policy of not applying CVDs to nonmarket economies. However, the US International Trade Commission has finally rejected the CVDs.
} 
violate the WTO agreements and proceed to the settlement of disputes under the WTO. ${ }^{4}$ For example, when the United States imposed a $18.79 \%$ CVD on softwood lumber from Canada in 2001, the Canadian government requested that the WTO establish a panel. Similarly, as the United States, the EU and Japan recently imposed CVDs on Korean DRAMs, panels were separately established at the request of the Korean government.

The purpose of this paper is to examine the effects of CVDs as well as those of subsidies in the exporting country in the presence of heterogeneity among exporting firms. Following Spencer (1988), capital subsidies are explored as well as direct export (or production) subsidies. Spencer (1988) says "In fact, many subsidies are directed towards capital investment, ..." and "... a direct export subsidy can always be exactly offset by a tariff of the same form which raises the same total revenue."

First, the effects of these two subsidies will be compared. Interestingly, capital subsidies may not benefit all recipients when they are heterogeneous in production. ${ }^{5}$ CVDs imposed to offset capital subsidies are then analyzed. Again, following Spencer (1988), two kinds of CVDs are considered, "equal-payment" tariffs and "equal-exports" tariffs. Under the equal-payment tariffs, the total tariff revenue is equal to the total subsidy payment. Under the equal-exports tariffs, the level of exports remains unchanged. The relationship between these two tariffs is explored and it is shown that equal-payment tariffs may be more than enough to offset the injury caused by capital subsidies.

It is somewhat surprising that there are not many studies on CVDs regardless of their frequent application. Dixit (1987) considers the optimal CVDs when direct export subsidies are exogenously provided. An export subsidy is partially countervailed by the optimal tariff. Extending Dixit (1987), Collie (1991) considers the optimal export subsidies with retaliation, i.e., tariffs and/or production subsidies. He shows that the optimal subsidy is usually negative in the presence of the optimal CVD retaliation. Noting that it takes time to introduce CVDs, Qiu (1995) specifically investigates how the timing of applying CVDs affects export subsidies in a dynamic model. He finds that CVDs reduce subsidies but the constraint on the amount of CVDs under the WTO as well as the delay in the imposition of CVDs fails to deter export subsidization. In contrast, Spencer (1988) is not concerned with the optimal responses in her analysis of CVDs. She focuses on the effectiveness of CVDs when facing exogenous capital subsidies in the exporting country. She explicitly takes the GATT rules of CVDs into account and shows that a small capital subsidy may improve welfare of the exporting country.

This analysis is along the lines of Spencer's (1988), because it also analyzes capital subsidies which, following the WTO rules, might be offset by CVDs. However, it specifically assumes that exporting firms are heterogeneous, that is, the labor and capital coefficients are different across exporting firms. This inter-firm asymmetry coupled with capital subsidies enables us to obtain deeper insights on subsides and CVDs.

In the context of strategic trade policy, there are several papers such as de Meza (1986) and Neary (1994) which are concerned with the cost asymmetries across countries. However, few studies deal with the cost asymmetries among firms exporting from the

\footnotetext{
${ }^{4}$ There are 11 panel cases concerning CVDs after the WTO was established in 1995.

${ }^{5}$ A similar result is obtained in Ishikawa and Komoriya (2007).
} 
same country. ${ }^{7}{ }^{7}$ Long and Soubeyran (1997) point out that when domestic firms have different unit costs, the Herfindahl index and the slope of the demand curve play a crucial role in determining trade policies. Collie (2006) compares the efficiency between ad valorem taxes/subsidies and specific taxes/subsidies and shows that ad valorem instruments have an additional effect on outputs compared to specific instruments. In the case of an ad valorem production subsidy, this additional effect reallocates production towards high-cost firms. Both the offshoring decisions and the welfare effects of trade costs in the presence of heterogeneous firms are analyzed elsewhere (Ishikawa and Komoriya, 2006, 2007).

The rest of this paper is organized as follows. Section 2 presents the basic model. Section 3 investigates the effects of subsidies. Section 4 explores the effects of CVDs. Section 5 concludes the paper.

\section{The Basic Model}

There are two countries (domestic and foreign), two domestic firms (firms 1 and 2), and a foreign firm. The firms produce a homogenous good and engage in Cournot competition in the foreign market. ${ }^{8}$ The domestic government subsidizes the domestic firms, which export all outputs to the foreign country. ${ }^{9}$ The foreign government may impose a tariff to offset the subsidy.

The inverse demand is given by the following linear function: ${ }^{10}$

$$
P(X)=b-a X,
$$

where $P$ and $X$ are, respectively, the price and the demand of the final good. $a$ and $b$ are parameters. In equilibrium, $X=x_{1}+x_{2}+x^{*}$ (where $x_{i}$ and $x^{*}$ are, respectively, the output of firm $i(i=1,2)$ and that of the foreign firm).

The good is produced by using capital services and labor. The cost function of firm $i(i=1,2)$ is given by

$$
C_{i}\left(x_{i}\right)=\left(\alpha_{i} w+\beta_{i} r\right) x_{i} \equiv c_{i} x_{i},
$$

${ }^{6}$ Papers such as Lahiri and Ono (1988) focus on the inter-firm cost asymmetry within a closed economy.

${ }^{7}$ Firm heterogeneity has recently attracted considerable attention in the international trade literature. However, most studies are on the basis of the monopolistic competition model originally developed by Melitz (2003), that considers the coexistence of exporting firms and non-exporting firms. See, for example, Helpman et al. (2004) and Grossman et al. (2006).

${ }^{8}$ The essence of our results would not change even if the firms engage in Bertrand competition instead of Cournot competition.

${ }^{9}$ This analysis assumes away FDI by the domestic firms. Firms refrain from FDI in the presence of high setup costs of FDI and high risk of expropriation, for example.

${ }^{10}$ Linear demand is not crucial to the main results. 
where $\alpha_{i}$ and $\beta_{i}$ are labor and capital coefficients, and $w$ and $r$ are the wage and rental rates. It is assumed that the coefficients and factor prices are exogenously given and constant. Without loss of generality, it is assumed that $\beta_{1}<\beta_{2}{ }^{11}$

The domestic government uses either a specific export subsidy, $v$, or a subsidy per unit of capital services, $s .{ }^{12}$ This analysis focuses on non-negative subsidies. The foreign government may impose a specific tariff, $t$, to offset subsidies. The profits of firm $i(i=1,2)$ are given by

$$
\Pi_{i}=P(X) x_{i}-\left[\alpha_{i} w+\beta_{i}(r-s)+t-v\right] x_{i}
$$

and those of the foreign firm are given by

$$
\Pi^{*}=P(X) x^{*}-c^{*} x^{*}
$$

where $c^{*}$ is the constant MC for the foreign firm.

Given the subsidies and tariffs, the equilibrium output and profits of each firm are ${ }^{13}$

$$
\begin{aligned}
& \bar{x}_{1}(t)=\frac{b+\rho_{2}+c^{*}-3 \rho_{1}}{4 a}, \\
& \bar{x}_{2}(t)=\frac{b+\rho_{1}+c^{*}-3 \rho_{2}}{4 a}, \\
& \bar{x}^{*}(t)=\frac{b+\rho_{1}+\rho_{2}-3 c^{*}}{4 a}, \\
& \bar{\Pi}_{1}=a\left(\bar{x}_{1}\right)^{2}, \bar{\Pi}_{2}=a\left(\bar{x}_{2}\right)^{2}, \bar{\Pi}^{*}=a\left(\bar{x}^{*}\right)^{2},
\end{aligned}
$$

where $\rho_{i} \equiv c_{i}+t-v-\beta_{i} s(i=1,2)$. In the following, $\rho_{i}$ is called the "effective" MC. In view of (5), the profits of a firm rise if and only if its output rises.

\section{Subsidies}

In this section, the effects of subsidies alone are examined. First, export subsidies are considered by setting $t=s=0$. This gives

$$
\frac{d \bar{x}_{1}}{d v}=\frac{d \bar{x}_{2}}{d v}=\frac{1}{2 a}>0, \frac{d \bar{x}^{*}}{d v}=-\frac{1}{2 a}<0, \frac{d \bar{X}}{d v}=\frac{1}{2 a}>0 .
$$

\footnotetext{
${ }^{11}$ If $\beta_{1}=\beta_{2}$, then export subsidies and capital subsidies are equivalent.

${ }^{12}$ Since all outputs are exported, export subsidies and production subsidies are equivalent.

${ }^{13}$ Equilibrium values are denoted by the upper bar.
} 
Thus, an export subsidy increases the outputs and profits of both domestic firms and decreases those of the foreign firm. This is because the export subsidy shifts rents from the foreign firm to the domestic firms.

Next, capital subsidies are analyzed by setting $t=v=0$. We have

$$
\begin{aligned}
& \frac{d \bar{x}_{1}}{d s}=\frac{3 \beta_{1}-\beta_{2}}{4 a}, \frac{d \bar{x}_{2}}{d s}=\frac{3 \beta_{2}-\beta_{1}}{4 a}>0, \\
& \frac{d \bar{x}^{*}}{d s}=-\frac{\beta_{1}+\beta_{2}}{4 a}<0, \frac{d \bar{X}}{d s}=\frac{\beta_{1}+\beta_{2}}{4 a}>0 .
\end{aligned}
$$

In contrast to export subsidies, a capital subsidy may not increase the output of firm 1. Noting $\beta_{1}<\beta_{2}$, it can be concluded that both outputs rise if $\beta_{1}<\beta_{2}<3 \beta_{1}$, while only $x_{2}$ rises if $\beta_{2}>3 \beta_{1}$. The intuition of this counter-intuitive result is as follows. An increase in $v$ lowers the effective MCs of both domestic firms by the same amount, while an increase in $s$ lowers $\rho_{2}$ more than $\rho_{1}$. That is, the benefit from capital subsidies is asymmetric between firms 1 and 2 , and firm 2 benefits more than firm 1 . The subsidy to firm 2 generates the force to reduce the outputs of the other firms, because the outputs are strategic substitutes. When $\beta_{2}$ is large, firm 2 increases its output by a large amount and hence the force to reduce the firm 1's output could dominate the force to raise it caused by the subsidy.

Thus, the effects of subsidies on firms are as follows.

Proposition 1 Both domestic firms always gain from an export subsidy. A capital subsidy benefits both domestic firms if $\beta_{1}<\beta_{2}<3 \beta_{1}$ but benefits only firm 2 (the domestic firm with a higher capital coefficient) if $\beta_{2}>3 \beta_{1}$. Whether a subsidy is given to exports or capital, the foreign firm loses.

In the case of export subsidies, both domestic firms gain. However, this may not make the domestic country better off. Domestic welfare is measured by the sum of profits and the cost of subsidy

$$
W=\Pi_{1}+\Pi_{2}-S,
$$

where $S$ is the subsidy payment. It can be shown that

$$
\left.\frac{d \bar{W}}{d v}\right|_{\mathrm{V}=0}=0 .
$$

Thus, the maximum welfare is actually realized without any export subsidy, that is, the optimal export subsidy is zero. It should be noted that this result depends on linear demand and costs and the number of firms. In particular, as the number of exporting firms increases, the level of the optimal export subsidy decreases and eventually becomes negative (see Krishna and Thursby, 1991). Under linear demand and costs, the optimal export subsidy is zero if there are two domestic firms and a single foreign firm. 
The effect of a capital subsidy on domestic welfare is

$$
\frac{d \bar{W}}{d s}=\frac{\left(\bar{x}_{1}-\bar{x}_{2}\right)\left(\beta_{1}-\beta_{2}\right)}{2}-\frac{s}{4 a}\left(\beta_{1}+\beta_{2}\right)^{2} .
$$

Thus,

$$
\left.\frac{d \bar{W}}{d s}\right|_{\mathrm{S}=0}=\frac{\left(\bar{x}_{1}-\bar{x}_{2}\right)\left(\beta_{1}-\beta_{2}\right)}{2},
$$

which is positive if and only if $\bar{x}_{1}<\bar{x}_{2}$. Thus, the introduction of a capital subsidy enhances domestic welfare if $\bar{x}_{1}<\bar{x}_{2}$. It can easily be verified that

$$
\bar{x}_{1}<\bar{x}_{2} \Leftrightarrow w\left(\alpha_{1}-\alpha_{2}\right)>(r-s)\left(\beta_{2}-\beta_{1}\right) .
$$

Thus, (7) holds if and only if

$$
w\left(\alpha_{1}-\alpha_{2}\right)>r\left(\beta_{2}-\beta_{1}\right)
$$

Since $\beta_{1}<\beta_{2}, \alpha_{1}>\alpha_{2}$ is necessary for this. (9) is likely to hold when the wage-rental ratio is relatively high and/or when $\alpha_{1}$ is relatively high. The optimal subsidy is given by

$$
s^{O}=\left\{\begin{array}{cc}
\frac{2\left(\beta_{2}-\beta_{1}\right)\left\{w\left(\alpha_{1}-\alpha_{2}\right)-r\left(\beta_{2}-\beta_{1}\right)\right\}}{\left(\beta_{1}+\beta_{2}\right)^{2}} & \text { if } w\left(\alpha_{1}-\alpha_{2}\right)>r\left(\beta_{2}-\beta_{1}\right) \\
0 & \text { otherwise }
\end{array}\right.
$$

Foreign welfare is measured by the sum of the foreign profits and consumers surplus $C S$ :

$$
W^{*}=\Pi^{*}+C S \text {. }
$$

It is straightforward to show

$$
\frac{d \bar{W}^{*}}{d v}=\frac{\bar{x}_{1}+\bar{x}_{2}-\bar{x}^{*}}{2}
$$

Thus, a domestic export subsidy improves foreign welfare if and only if the foreign market share is less than 50\%. The critical market share " $50 \%$ " stems from linear demand. Even if the demand is non-linear, however, there exists a critical share level below (above) which a domestic subsidy improves (deteriorates) foreign welfare (see Ono, 1990 and Ishikawa, 1998). Intuitively, an export subsidy harms the foreign firm by decreasing its output but benefits the foreign consumers by increasing the total supply to the foreign market. When the share of the foreign firm is small, the loss of the foreign firm is relatively small and is dominated by the consumer gains. It should be mentioned that this result depends only on the foreign market share and hence holds with capital subsidies.

The above analysis established the following proposition. 
Proposition 2 A capital subsidy enhances domestic welfare if $w\left(\alpha_{1}-\alpha_{2}\right)>r\left(\beta_{2}-\beta_{1}\right)$, or, if the output of firm 1 is less than that of firm 2 under free trade. A domestic subsidy improves foreign welfare if and only if the foreign market share is less than 50\%.

\section{Countervailing Duties}

In this section, CVDs are explored. In the case of export subsidies, it is obvious that a specific subsidy is fully countervailed if a specific tariff is set at the same level. In the following, therefore, the case of capital subsidies is focused on.

Suppose that a capital subsidy is provided in the domestic country. Then, in view of (4) and (5), the output and profits of the foreign firm remain unchanged if a specific tariff is set at the level

$$
t=\frac{s\left(\beta_{1}+\beta_{2}\right)}{2}(\equiv \hat{t}(s)) .
$$

Following Spencer (1988), $\hat{t}$ is called the "equal-exports" tariff. Substituting $\hat{t}$ into (4) gives

$$
\bar{x}_{i}(\hat{t})=\frac{b+c_{j}+c^{*}-3 c_{i}+2 s\left(\beta_{i}-\beta_{j}\right)}{4 a},(i, j=1,2 ; i \neq j) .
$$

Thus, when the equal-exports tariff is imposed, the total effect of a capital subsidy on the outputs of the domestic firms are given by

$$
\begin{aligned}
& \frac{d \bar{x}_{1}}{d s}=\frac{\partial \bar{x}_{1}}{\partial s}+\frac{\partial \bar{x}_{1}}{\partial t} \frac{\partial \hat{t}}{\partial s}=\frac{\beta_{1}-\beta_{2}}{2 a}<0, \\
& \frac{d \bar{x}_{2}}{d s}=\frac{\partial \bar{x}_{2}}{\partial s}+\frac{\partial \bar{x}_{2}}{\partial t} \frac{\partial \hat{t}}{\partial s}=\frac{\beta_{2}-\beta_{1}}{2 a}>0, \frac{d\left(\bar{x}_{1}+\bar{x}_{1}\right)}{d s}=0 .
\end{aligned}
$$

The effects of $\hat{t}$ on the domestic firms are different across the firms. Whereas the output of firm 1 falls, that of firm 2 rises. This is because the tariff raises the effective MCs of both domestic firms by the same amount but the benefits of the subsidy are different between the domestic firms. The subsidy provided to firm 1 is excessively countervailed by $\hat{t}$, while that to firm 2 is insufficiently countervailed. Thus, when a capital subsidy is countervailed by an equal-export subsidy, firm 1 loses but firm 2 gains relative to free trade.

Under the WTO rules, the domestic government may not set a CVD the total tariff revenue of which is greater than the total payment of the subsidy. When the total amount of the CVD is equal to that of the subsidy, this gives

$$
t=\frac{s\left(\beta_{1} \bar{x}_{1}(\widetilde{t})+\beta_{2} \bar{x}_{2}(\tilde{t})\right)}{\bar{x}_{1}(\tilde{t})+\bar{x}_{2}(\tilde{t})} \equiv \tilde{t},
$$


which is referred to as the "equal-payment" tariff in Spencer (1988) and is the maximum CVD rate allowed under the WTO.

The subsidy per unit of output is compared with the equal-payment tariff rate:

$$
\begin{aligned}
& s \beta_{1}-\tilde{t}=\frac{\left(\beta_{1}-\beta_{2}\right) s x_{2}(\tilde{t})}{\bar{x}_{1}(\tilde{t})+\bar{x}_{2}(\tilde{t})}<0, \\
& s \beta_{2}-\tilde{t}=\frac{\left(\beta_{2}-\beta_{1}\right) s x_{1}(\tilde{t})}{\bar{x}_{1}(\tilde{t})+\bar{x}_{2}(\tilde{t})}>0 .
\end{aligned}
$$

As in the case of the equal-exports tariff, firm 1 is excessively countervailed, while firm 2 is insufficiently countervailed.

Next, the equal-exports tariff is compared with the equal-payment tariff:

$$
\tilde{t}-\hat{t}=\frac{s\left(\bar{x}_{2}(\tilde{t})-\bar{x}_{1}(\tilde{t})\right)\left(\beta_{2}-\beta_{1}\right)}{2\left(\bar{x}_{1}(\tilde{t})+\bar{x}_{2}(\tilde{t})\right)},
$$

which is positive if and only if $\bar{x}_{1}(\tilde{t})<\bar{x}_{2}(\tilde{t})$ Thus, the foreign firm benefits from the equal-payment tariff if and only if $\bar{x}_{1}(\tilde{t})<\bar{x}_{2}(\tilde{t})$. Since (8) is independent of the tariff rate,

$$
\begin{aligned}
\tilde{t} & >\hat{t} \Leftrightarrow \bar{x}_{1}(\widetilde{t})<\bar{x}_{2}(\widetilde{t}) \\
& \Leftrightarrow w\left(\alpha_{1}-\alpha_{2}\right)>(r-s)\left(\beta_{2}-\beta_{1}\right) \\
& \Leftrightarrow s>r-w \frac{\alpha_{1}-\alpha_{2}}{\beta_{2}-\beta_{1}} \equiv \hat{s} .
\end{aligned}
$$

It is obvious that $\bar{x}_{1}(\tilde{t})<\bar{x}_{2}(\tilde{t})$ holds only if $\alpha_{2} \leq \alpha_{1}$, because $\beta_{2}>\beta_{1}$. Conversely, $\bar{x}_{1}>\bar{x}_{2}$ holds if $\alpha_{2} \geq \alpha_{1}$. Figure 1 shows the relationship between the equal-payment tariff and the equal-exports tariff. There are two cases depending on the size of $\hat{s}$. In Panel (a), $\tilde{t}$ intersects $\hat{t}$ at $\hat{s}$. The equal-payment tariff is more than enough to remove the injury to the foreign firm if $s>\hat{s}$ but is not enough if $s<\hat{s}$. This implies that a CVD which is smaller than the equal-payment tariff is adequate to remove the injury if $s$ is large enough. In Panel (b), $\hat{s}$ is negative and $\tilde{t}$ is located above $\hat{t}$. Hence the equal-payment tariffs are more than enough to offset the injury. 


\section{Figure 1}

\section{Equal-Exports Tariff, Equal-Payment Tariff, and Optimal Tariff}
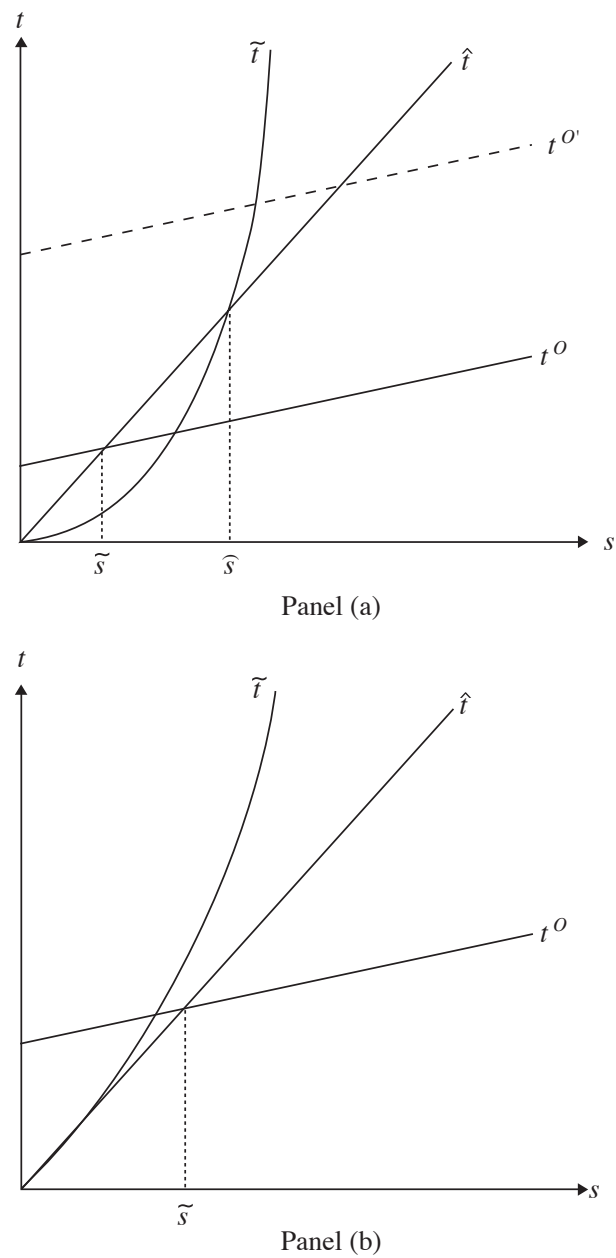

Thus, the following proposition is obtained.

Proposition 3 Suppose that a capital subsidy is offset by a CVD. Whether the CVD is the equal-exports tariff or the equal-payment tariff, firm 1 loses but firm 2 still gains from the subsidy. When the equal-payment tariff is used to countervail the capital subsidy, the foreign firm benefits from the subsidy if and only if $s>\max \{0, \hat{s}\}$.

In the presence of the equal-exports tariff, the foreign firm is indifferent between with and without the subsidy. However, the subsidy makes the foreign country better off, because the equal-exports tariff generates tariff revenue without affecting the total supply to the foreign country. On the other hand, it can be shown that the domestic country is always made worse off. Noting (12), the following is obtained: 


$$
\begin{aligned}
\frac{d \bar{W}}{d s} & =2 a \bar{x}_{1} \frac{d \bar{x}_{1}}{d s}+2 a \bar{x}_{2} \frac{d \bar{x}_{2}}{d s}-\left(\beta_{1} \bar{x}_{1}+\beta_{2} \bar{x}_{2}\right)-s\left(\beta_{1} \frac{d \bar{x}_{1}}{d s}+\beta_{2} \frac{d \bar{x}_{2}}{d s}\right) \\
& =-\beta_{2} \bar{x}_{1}-\beta_{1} \bar{x}_{2}-\frac{s\left(\beta_{1}-\beta_{2}\right)^{2}}{2 a}<0 .
\end{aligned}
$$

Thus, a capital subsidy, which is countervailed by the equal-exports tariff, deteriorates domestic welfare relative to free trade.

Proposition 4 A capital subsidy is harmful to the domestic country but is beneficial to the foreign country if it is countervailed by the equal-exports tariff.

The equal-payment tariff may or may not improve foreign welfare relative to the equal-exports tariff. To see this, we need to derive the optimal tariff. Given $s$, the effect of a tariff on foreign welfare is given by

$$
\begin{aligned}
\frac{\partial \bar{W}^{*}}{\partial t} & =\frac{\bar{X}}{2}-\frac{t}{a} \\
& =\frac{1}{2}\left(\frac{3 b-\alpha_{1} w-\beta_{1}(r-s)-\alpha_{2} w-\beta_{2}(r-s)-c^{*}-2 t}{4 a}\right)-\frac{t}{a} \\
& =\frac{1}{2}\left(\frac{3 b-\alpha_{1} w-\beta_{1} r-\alpha_{2} w-\beta_{2} \mathrm{r}-c^{*}}{4 a}\right)+\frac{s\left(\beta_{1}+\beta_{2}\right)}{8 a}-\frac{5 t}{4 a} \\
& =\frac{\bar{X}^{f}}{2}+\frac{s\left(\beta_{1}+\beta_{2}\right)}{8 a}-\frac{5 t}{4 a},
\end{aligned}
$$

where the superscript " $f$ " stands for variables under free trade. The optimal tariff is

$$
\begin{aligned}
t^{O} & =\frac{2 a X^{f}}{5}+\frac{s\left(\beta_{1}+\beta_{2}\right)}{10} \\
& =\frac{\left(3 b-\alpha_{1} w-\beta_{1} r-\alpha_{2} w-\beta_{2} r-c^{*}\right)}{10}+\frac{s\left(\beta_{1}+\beta_{2}\right)}{10}>0,
\end{aligned}
$$

which implies that $t^{O}$ is linear with respect to $s$. Comparing $\hat{t}$ and $t^{O}$ gives

$$
\begin{aligned}
\hat{t} & \geq t^{O} \Leftrightarrow \frac{s\left(\beta_{1}+\beta_{2}\right)}{2} \geq \frac{2 a \bar{X}^{f}}{5}+\frac{s\left(\beta_{1}+\beta_{2}\right)}{10} \\
& \Leftrightarrow s \geq \frac{a \bar{X}^{f}}{\left(\beta_{1}+\beta_{2}\right)} \\
& \Leftrightarrow s \geq \frac{3 b-\alpha_{1} w-\beta_{1} r-\alpha_{2} w-\beta_{2} r-c^{*}}{4\left(\beta_{1}+\beta_{2}\right)} \equiv \tilde{s} .
\end{aligned}
$$


By noting $\bar{x}_{1}=\bar{x}_{1}^{f}+s\left(3 \beta_{1}-\beta_{2}\right) / 4 a$ and $\bar{x}_{2}=\bar{x}_{2}^{f}+s\left(3 \beta_{2}-\beta_{1}\right) / 4 a$, the condition under which $\tilde{s}$ is greater than or equal to $\hat{s}$ is

$$
\begin{aligned}
\tilde{s} & \geq \hat{s} \Leftrightarrow \frac{a \bar{X}^{f}}{\left(\beta_{1}+\beta_{2}\right)} \geq \frac{a\left(\bar{x}_{2}^{f}-\bar{x}_{1}^{f}\right)}{\beta_{1}-\beta_{2}} \\
& \Leftrightarrow \frac{\beta_{2}-\beta_{1}}{\beta_{1}+\beta_{2}} \geq \theta_{1}^{f}-\theta_{2}^{f},
\end{aligned}
$$

where $\theta_{i}^{f}$ is the market share of domestic firm $i$ under free trade. This condition obviously holds if $\theta_{2}^{f}>\theta_{1}^{f}$.

If either $t^{O} \leq \hat{t}<\tilde{t}$ or $\tilde{t}<\hat{t} \leq t^{O}$ holds, foreign welfare under the equal-payment tariff is lower than that under the equal-exports tariff. $t^{O} \leq \hat{t}<\tilde{t}$ necessarily holds if $s>\max$ $\{\hat{s}, \tilde{s}\}$, while $\tilde{t}<\hat{t} \leq t^{O}$ necessarily holds if $s<\min \{\hat{s}, \tilde{s}\}$. If either $\hat{t}<t^{O}<\tilde{t}$ or $\tilde{t}<t^{O}<\hat{t}$ holds, on the other hand, welfare under the equal-payment tariff may or may not be lower than that under the equal-exports tariff.

It should be noted that subsidies make the domestic country worse off relative to free trade when being countervailed by tariffs whose rates are higher than or equal to $\hat{t}$. As seen in the last section, in the absence of CVDs, the welfare-improving subsidy is a capital subsidy, provided firm 2 is more efficient than firm 1. Once CVDs on the basis of either the equal-exports tariff or the equal-payment tariff are introduced in the foreign country, however, such a subsidy deteriorates domestic welfare relative to free trade. This is because tariff rates are higher than or equal to $\hat{t}$ when firm 2 is more efficient than firm 1 .

\section{Concluding Remarks}

The effects of export subsidies and capital subsidies in the presence of firm heterogeneity have been identified. An interesting result is that capital subsidies do not necessarily benefit all recipients. Two types of foreign CVDs to offset domestic capital subsidies have been explored. When a capital subsidy is offset by the equal-exports tariff, the foreign firm is indifferent. However, the effect of the equal-payment tariff on the foreign firm depends on the subsidy rate as well as the parameter values. Only if the subsidy rate is relatively low, the effect of the equal-payment tariff fails to recover the foreign firm's loss from the subsidy. Moreover, whether CVDs are the equal-payment tariff or the equal-exports tariff, the domestic firm with lower (higher) capital coefficient is excessively (insufficiently) countervailed. As a result, a domestic capital subsidy coupled with a foreign CVD harms the domestic firm with lower capital coefficient but benefits the other domestic firm. This analysis suggests that the rational domestic government would not subsidize the domestic firms when anticipating CVDs. However, the domestic firm with the higher capital coefficient has an incentive to lobby for capital subsidies even if CVDs are anticipated. The equal-export tariff benefits the foreign country, while the equal-payment tariff may or may not enhance foreign welfare relative to the equal-exports tariff. 


\section{References}

Brander, J.A. and B.J. Spencer, 1985, "Export Subsidies and International Market Rivalry," Journal of International Economics 18, 83-100.

Collie, D., 1991, "Export Subsidies and Countervailing Tariffs," Journal of International Economics 31, 309-324.

Collie, D., 2006, "Tariffs and Subsidies under Asymmetric Oligopoly: Ad Valorem and Specific Instruments," Manchester School 74, 314-333.

de Meza, D., 1986, "Export Subsidies and High Productivity: Cause or Effect?" Canadian Journal of Economics 19, 347-350.

Dixit, A.K., 1987, “Anti-dumping and Countervailing Duties under Oligopoly,” European Economic Review 32, 55-68.

Grossman, G.M., E. Helpman and A. Szeidl, 2006, “Optimal Integration Strategies for the Multinational Firm," Journal of International Economics 70, 216-238.

Helpman, E., M.J. Melitz and S.R. Yeaple, 2004, "Export Versus FDI with Heterogeneous Firms," American Economic Review 94, 300-316.

Industrial Structure, Council, METI, Japan, 2007, 2007 Report on the WTO Inconsistency of Trade Policies by Major Trading Partners.

Ishikawa, J., 1998, "Who Benefits from Voluntary Export Restraints?" Review of International Economics 6, 129-141.

Ishikawa, J. and Y. Komoriya, 2006, "Stay or Leave? Choice of Plant Location with Cost Heterogeneity," COE/RES Discussion Paper Series, No. 168, Hitotsubashi University.

Ishikawa, J. and Y. Komoriya, 2007, “Trade Costs, Wage Rates, Technologies, and Offshore Outsourcing," mimeo.

Itoh, M. and K. Kiyono, 1987, “Welfare Enhancing Export Subsidies,” Journal of Political Economy 95, 115-137.

Krishna, K. and M. Thursby, 1991, “Optimal Policies with Strategic Distortions,” Journal of International Economics 31, 291-308.

Lahiri, S. and Y. Ono, 1988, "Helping Minor Firms Reduces Welfare," Economic Journal 98, 1199-1202.

Long, N.V. and A. Soubeyran, 1997, "Cost Heterogeneity, Industry Concentration and Strategic Trade Policies," Journal of International Economics 43, 207-220.

Melitz, M.J., 2003, “The Impact of Trade on Intra-industry Reallocations and Aggregate Industry Productivity," Econometrica 71, 1695-1725.

Neary, J.P., 1994, “Cost Asymmetries in International Subsidy Games: Should Government Help Winners and Losers?” Journal of International Economics 37, 197-218.

Ono, Y., 1990, "Foreign Penetration and National Welfare under Oligopoly," Japan and the World Economy 2, 141-154.

Qiu, L.D., 1995, “Why Can't Countervailing Duties Deter Export Subsidies?” Journal of International Economics 39, 249-272.

Spencer, B.J., 1988, "Capital Subsidies and Countervailing Duties in Oligopolistic Industries," Journal of International Economics 25, 45-69. 